\title{
Age-related changes in peripheral blood counts in humans
}

\author{
ULRICH MAHLKNECHT $^{1,2}$ and SIMONE KAISER ${ }^{2}$ \\ ${ }^{1}$ Department of Immunotherapy and Gene Therapy, Saarland University Medical Center, Homburg/Saar; \\ ${ }^{2}$ Department of Hematology/Oncology, University of Heidelberg Medical Center, Heidelberg, Germany
}

Received July 9, 2010; Accepted September 6, 2010

DOI: $10.3892 / \mathrm{etm} .2010 .150$

\begin{abstract}
Anaemia has become a common concern in geriatric health. Since its prevalence varies quite significantly among different groups depending on factors such as ethnicity, lifestyle or fitness, the appropriateness of the current WHO definition of anaemia in the elderly may be questioned. We evaluated peripheral blood parameters from 1,724 individuals (908 women aged 18-101 years and 816 men aged 18-96 years), who were treated at the University of Heidelberg Medical Center with no known haematological history. Patients with a known malignant haematological or oncological disease or with chronic infection or inflammation were excluded. Patients with disorders affecting the kidneys, thyroid or stomach, as well as patients with a bleeding history, haemolysis or who had been previously diagnosed with anaemia were excluded from the study. Average haemoglobin levels for men beyond the age of 70 and for women beyond the age of 80 were found to fulfill the WHO criteria for the diagnosis of anaemia. While in our cohort $20 \%$ of men and women between 60-69 years of age were by definition anaemic, these numbers steadily increased to $63 \%$ in females and $76 \%$ in males beyond the age of 90 . Based on the results of our study and in accordance with the literature on this topic, we suggest age-adjusted criteria for the diagnosis of anaemia in the elderly in conjunction with a geriatric assessment.
\end{abstract}

\section{Introduction}

For many years, particularly in view of the increasingly ageing population in the Western world, haematologists have had a profound interest in researching the the pathophysiology and clinical relevance of anaemia in association with aging. Despite the fact that numerous studies show a link between lower haemoglobin levels and morbidity and/or mortality, this is also the case for elevated or upper normal haemoglobin levels (1), which may be associated with secondary polycythaemia; e.g.,

Correspondence to: Dr Ulrich Mahlknecht, Department of Immunotherapy and Gene Therapy, Saarland University Medical Center, Kirrberger Strasse, Bldg. 45.3, D-66424 Homburg/Saar, Germany

E-mail: ulrich.mahlknecht@uks.eu

Key words: haemoglobin, haematopoiesis, ageing, epigenetics associated with underlying pulmonary or cardiac disease, or resulting from increased blood viscosity as has been reported with the use of erythropoiesis-stimulating agents, which may increase the risk for thromboembolic events (2). Numerous studies have been carried out on anaemia in distinct ethnic or geographic populations (3-8), in children (9-12), elderly people $(4,6,8,13)$ and pregnant women $(14)$. Differences noted in such studies may not only be explained by lifestyle and environmental factors, they may also and most essentially be explained by different exclusion criteria that have been used in these studies.

Presently, there are nearly 500 million (7\%) adults 65 years or older in the world, but by 2030 this population will double to 1 billion (12\%) worldwide $(15,16)$. In Germany, the increasingly ageing population will be paralleled by a continuously shrinking total population, which is currently 81.5 million (as reported for the year 2010) and which will decrease to 77.4 million by the year 2030 and to 64.7 million by 2060. Thus, the number of people beyond the age of 65 currently accounts for $20.6 \%$ of the total population (16.8 million) (2010), while in 2030 this proportion will rise to $28.7 \%$ of the total population, and in 2050 this percentage will climb to $33 \%$ of the total German population (16). This means that by the year 2050 the number of taxpayers in Germany will roughly be equal to the number of people beyond the age of 65 .

Since ageing is a process that results from the accumulation of somatic damage, which increases the risk of mortality (17), there is a profound desire to assess the risk of mortality on the basis of laboratory parameters. The evaluation of haemoglobin levels in the elderly is a complex task, since it is difficulty to assess whether a haemoglobin level beyond the normal range in a given individual is the result of an underlying disease or whether it is a phenomenon of the expression of age (4). Numerous factors have been described as affecting blood counts in the elderly. Reduced numbers of haematopoietic stem cells, the finite number of cell divisions (18), a defect in progenitor cell proliferation (19), the inability to sufficiently mobilize such progenitors (6), and the lack of hormonal stimulation or the reduced response to hormonal stimulation (20-23) are a few examples of conditions that may concur with reduced haemoglobin levels in the absence of an apparent illness.

Taking the current definition of the World Health Organization, which defines anaemia as haemoglobin levels of $\leq 12.0 \mathrm{~g} / \mathrm{dl}$ for women and $\leq 13.0 \mathrm{~g} / \mathrm{dl}$ for men, we may run into a most significant public health crisis in the near future. In view of the fact that anaemia is a common and most frequently 
an underestimated condition in the elderly, several key questions should be addressed in order to better understand the following: i) to what extent anaemia in the elderly is the result of pre-existing disorders, ii) to what extent it predetermines potential subsequent morbidity, and iii) to what extent public health improvements could make a difference. In this context, it may be important to reflect on whether the current definition of anaemia by the World Health Organization is still adequate to define anaemia in the elderly, or whether new definitions for different elderly subpopulations would aid in more adequately describing the association of specific haemoglobin levels in the context of actual patient morbidity. Finally, but of equal importance, discussion should be initiated regarding the appropriate management of anaemia in the elderly and the economic implications to health care systems.

The objective of the study presented herein, was to examine the influence of increasing age on peripheral blood parameters obtained from hospitalized individuals with no known haematological history and to identify criteria which could be useful in the discussion of age-dependent reference values. Data from 1,724 individuals in the age range between 18 and 101 years were evaluated with particular consideration for red and white blood cell parameters and platelet counts.

\section{Materials and methods}

Patients. The study population comprised 1,724 individuals (908 women aged 18-101 years and 816 men aged 18-96 years) with no known haematological history who were treated at the University of Heidelberg Medical Center as inpatients or outpatients. All blood samples were obtained using routine diagnostic procedures. Haematological parameters and clinical chemistry were analyzed at the University of Heidelberg Medical Center central laboratory. Patients with a known malignant haematological or oncological disease, with chronic infection or inflammation were excluded. Patients with disorders affecting the kidneys, thyroid or stomach as well as patients with a bleeding history, haemolysis or who had been previously diagnosed to have anaemia were also excluded from this study. All samples were anonymized, and all data were handled confidentially. This study was carried out in accordance with the local ethics committee in agreement with the Declaration of Helsinki. The composition of the study population is outlined in Table I.

Statistical procedures. Mean, median and standard deviation were calculated for every haematological parameter in each study group. Outliers were defined as arguments beyond the reference interval that corresponded to the mean \pm 2 standard deviations (SD), and were not considered for the further calculation of mean values and SD. Age-dependent reference ranges were proposed on the basis of the $95 \%$ confidence intervals (mean $\pm 2 \mathrm{SD}$ ) for a specific parameter in a defined age group. The Kolmogorow-Smirnow test was carried out in order to find out whether the included arguments follow a Gaussian distribution. When a Gaussian distribution was confirmed, the Student's t-test was carried out in order to test for significant differences. Alternatively, the Wilcoxon U-test was carried out.

\section{Results}

The reference intervals for blood counts as used at the University Medical Center Heidelberg and the new reference intervals that were calculated by gender for specific age groups are shown in Table I.

With the exception of platelet and neutrophil counts, values were persistently higher in men than in women. These gender differences were most prominent in the younger age groups, and decreased continuously with increasing age. The most obvious age-dependent changes were observed for erythropoiesis-related parameters. A statistically significant $(\mathrm{p}<0.0001)$ age-dependent decline in haemoglobin levels was observed for both genders (Fig. 1). This decline was paralleled by the decline in age-dependent haematocrit levels in both genders $(\mathrm{p}<0.0001)$, and was more pronounced in men than in women. We evaluated peripheral blood parameters from 1,724 hospitalised individuals between the ages of 18 and 101 years with no known haematological history, who were admitted at the University of Heidelberg Medical Center for a medical or surgical condition. The average haemoglobin levels for men beyond the age of 70 and for women beyond the age of 80 were found to fulfil the WHO criteria for the diagnosis of anaemia, which are set at haemoglobin levels of $\leq 12.0 \mathrm{~g} / \mathrm{dl}$ for women and $\leq 13.0 \mathrm{~g} / \mathrm{dl}$ for men (Figs. 1 and 2). In contrast to haemoglobin, erythrocyte counts and haematocrit, the values for mean corpuscular volume (MCV) steadily increased in an age-dependent manner $(\mathrm{p}<0.0001)$, while the age-dependent increase in mean corpuscular haemoglobin levels was only statistically significant in males $(\mathrm{p}>0.0001)$ and not in females $(\mathrm{p}=0.359)$ when individuals below and beyond the age of 60 were compared.

In our cohort, $23 \%$ of all women between 60 and 69 years of age were diagnosed as anaemic according to the WHO criteria. This percentage increased to $36 \%$ in all female individuals between 70 and 79 years of age and $45 \%$ in all female individuals between 80 and 89 years of age. Sixty-three percent of all female individuals beyond the age of 90 were anaemic by definition. In the male population, these figures were even more dramatic. In the age-range between 60 and 69 years, $20 \%$ fulfilled the WHO criteria for anaemia, and $49 \%$ of all male individuals between 70 and 79 years of age, $70 \%$ of all male individuals between 80 and 89 years of age and $76 \%$ of all male individuals beyond the age of 90 were identified as anaemic according to the WHO criteria for the diagnosis of anaemia (Fig. 2).

In contrast to almost all other haematopoiesis parameters, which were higher in male individuals throughout all age groups, platelet counts were higher in female individuals in all evaluated age groups (Fig. 1), and showed a significant age-related decline in both genders $(p<0.0001)$. However, the measured platelet levels remained within the reference limits in use by the University of Heidelberg Medical Center and in accordance with the German Accreditation Council (DAR).

While the WBC mean values showed an age-dependent decreasing trend for both genders, no statistical significance was noted when individuals below and beyond the age of 60 years were compared to each other. However, when the cut-off age was set at 70 years, statistical significance was reached 
Table I. Age-adjusted reference intervals for women and men as calculated from age group-dependent mean values \pm 2 SD (rows 3-9). ${ }^{a}$

\begin{tabular}{|c|c|c|c|c|c|c|c|c|c|c|}
\hline & \multirow[b]{2}{*}{ Reference values } & \multicolumn{9}{|c|}{ Age (years) } \\
\hline & & $18-19$ & $20-29$ & $30-39$ & $40-49$ & $50-59$ & $60-69$ & $70-79$ & $80-89$ & $\geq 90$ \\
\hline \multicolumn{11}{|l|}{ Women } \\
\hline \multirow[t]{2}{*}{$\mathrm{Hb}$} & \multirow[t]{2}{*}{$12-15 \mathrm{~g} / \mathrm{dl}$} & 11.6 & 11.9 & 11.8 & 11.6 & 12.1 & 10.5 & 10.2 & 9.3 & 8.8 \\
\hline & & 15.0 & 15.3 & 14.9 & 15.0 & 15.3 & 15.3 & 14.8 & 14.9 & 14.3 \\
\hline No. & \multirow{3}{*}{$4.0-5.2 / \mathrm{pl}$} & 36 & 105 & 115 & 114 & 121 & 100 & 120 & 112 & 50 \\
\hline \multirow[t]{2}{*}{$\mathrm{RBC}$} & & 3.8 & 3.9 & 3.8 & 3.7 & 3.8 & 3.4 & 3.3 & 3.0 & 2.8 \\
\hline & & 5.1 & 5.2 & 5.1 & 5.1 & 5.2 & 5.1 & 5.0 & 5.0 & 5.0 \\
\hline No. & \multirow{3}{*}{$0.36-0.471 / 1$} & 36 & 104 & 115 & 115 & 122 & 100 & 122 & 113 & 51 \\
\hline \multirow[t]{2}{*}{ Hct } & & 0.33 & 0.34 & 0.34 & 0.33 & 0.35 & 0.31 & 0.29 & 0.26 & 0.25 \\
\hline & & 0.45 & 0.45 & 0.43 & 0.44 & 0.45 & 0.45 & 0.44 & 0.45 & 0.42 \\
\hline No. & & 35 & 101 & 106 & 110 & 107 & 91 & 116 & 109 & 50 \\
\hline \multirow{2}{*}{$\mathrm{MCV}$} & \multirow[t]{2}{*}{$83-97 \mathrm{fl}$} & 78.2 & 79.3 & 77.9 & 79.7 & 83.7 & 80.9 & 80.3 & 80.4 & 78.0 \\
\hline & & 94.7 & 94.0 & 97.2 & 98.3 & 97.7 & 97.3 & 97.8 & 97.6 & 102.1 \\
\hline No. & & 33 & 103 & 111 & 112 & 113 & 101 & 122 & 109 & 49 \\
\hline \multirow[t]{2}{*}{$\mathrm{MCH}$} & \multirow[t]{2}{*}{$27-33 \mathrm{pg}$} & 26.9 & 27.3 & 26.4 & 27.3 & 28.1 & 27.6 & 26.9 & 27.0 & 26.1 \\
\hline & & 33.4 & 32.7 & 34.0 & 34.0 & 34.8 & 33.5 & 34.1 & 33.7 & 35.5 \\
\hline No. & & 33 & 105 & 115 & 112 & 122 & 100 & 121 & 111 & 49 \\
\hline \multirow{2}{*}{ Plt } & \multirow[t]{2}{*}{$150-440 / \mathrm{nl}$} & 401.91 & 404.03 & 412.82 & 406.53 & 442.40 & 385.91 & 443.72 & 388.04 & 360.02 \\
\hline & & 157.18 & 160.03 & 175.79 & 156.15 & 179.04 & 146.15 & 122.37 & 125.33 & 117.79 \\
\hline & \multirow{3}{*}{$4.0-10.0 / \mathrm{nl}$} & 35 & 103 & 114 & 114 & 117 & 99 & 119 & 113 & 50 \\
\hline \multirow{2}{*}{ WBC } & & 2.2 & 3.9 & 3.6 & 3.7 & 4.6 & 3.2 & 4.5 & 4.2 & 4.0 \\
\hline & & 12.5 & 10.9 & 11.3 & 11.9 & 12.0 & 10.2 & 10.9 & 11.0 & 9.8 \\
\hline No. & & 36 & 102 & 112 & 115 & 116 & 99 & 121 & 112 & 48 \\
\hline \multicolumn{11}{|l|}{ Men } \\
\hline \multirow[t]{2}{*}{$\mathrm{Hb}$} & \multirow[t]{2}{*}{$13-17 \mathrm{~g} / \mathrm{dl}$} & 13.5 & 13.5 & 13.3 & 13.0 & 12.1 & 11.7 & 9.9 & 9.6 & 9.7 \\
\hline & & 17.5 & 16.9 & 17.0 & 16.7 & 16.6 & 16.3 & 16.0 & 14.9 & 14.8 \\
\hline No. & & 19 & 98 & 109 & 115 & 102 & 101 & 104 & 113 & 20 \\
\hline \multirow[t]{2}{*}{$\mathrm{RBC}$} & $4.3-6.1 / \mathrm{pl}$ & 4.3 & 4.4 & 4.3 & 4.3 & 3.9 & 3.7 & 3.3 & 3.0 & 2.9 \\
\hline & & 5.9 & 5.7 & 5.7 & 5.4 & 5.4 & 5.4 & 5.3 & 4.8 & 4.9 \\
\hline No. & & 19 & 100 & 110 & 111 & 101 & 101 & 104 & 114 & 20 \\
\hline Hct & $0.38-0.52$ 1/1 & 0.40 & 0.39 & 0.38 & 0.37 & 0.35 & 0.34 & 0.29 & 0.27 & 0.28 \\
\hline & & 0.49 & 0.49 & 0.49 & 0.48 & 0.47 & 0.48 & 0.46 & 0.44 & 0.44 \\
\hline No. & & 17 & 93 & 107 & 113 & 98 & 102 & 101 & 109 & 20 \\
\hline $\mathrm{MCV}$ & $83-97 \mathrm{fl}$ & 82.0 & 80.2 & 77.6 & 81.0 & 80.6 & 79.9 & 81.4 & 82.0 & 85.1 \\
\hline & & 90.8 & 94.6 & 96.2 & 95.3 & 98.8 & 100.1 & 97.2 & 100.7 & 98.4 \\
\hline No. & & 18 & 100 & 113 & 115 & 99 & 104 & 100 & 109 & 20 \\
\hline $\mathrm{MCH}$ & $27-33 \mathrm{pg}$ & 28.3 & 27.7 & 27.3 & 28.2 & 27.9 & 27.7 & 27.5 & 26.9 & 28.8 \\
\hline & & 32.3 & 33.0 & 33.5 & 33.0 & 34.4 & 34.2 & 33.9 & 35.9 & 34.6 \\
\hline No. & & 18 & 97 & 112 & 112 & 99 & 102 & 105 & 113 & 20 \\
\hline Plt & $150-440 / \mathrm{nl}$ & 183.7 & 157.8 & 162.8 & 150.8 & 136.5 & 123.9 & 82.8 & 104.8 & 137.4 \\
\hline & & 342.0 & 336.7 & 366.9 & 366.9 & 377.6 & 374.7 & 385.2 & 307.2 & 292.7 \\
\hline No. & & 18 & 99 & 111 & 113 & 101 & 99 & 102 & 110 & 20 \\
\hline WBC & $4.0-10.0 / \mathrm{nl}$ & 3.7 & 4.0 & 4.4 & 4.2 & 4.3 & 3.9 & 4.1 & 4.2 & \\
\hline & & 11.5 & 11.8 & 11.2 & 10.9 & 11.4 & 11.8 & 11.1 & 10.5 & 4.99 .8 \\
\hline No. & & 18 & 100 & 110 & 112 & 99 & 100 & 104 & 108 & 20 \\
\hline
\end{tabular}

aThe values indicated in the 2nd row are the reference values used by the University of Heidelberg Medical Center set and validated in accordance with the German Accreditation Council (DAR). No., number of individuals in the corresponding age group. Hb, haemoglobin; $\mathrm{RBC}$, red blood cell count; Hct, haematocrit; MCV, mean corpuscular volume; $\mathrm{MCH}$, mean corpuscular haemoglobin level; Plt, platelet count; WBC, white blood cell count. 

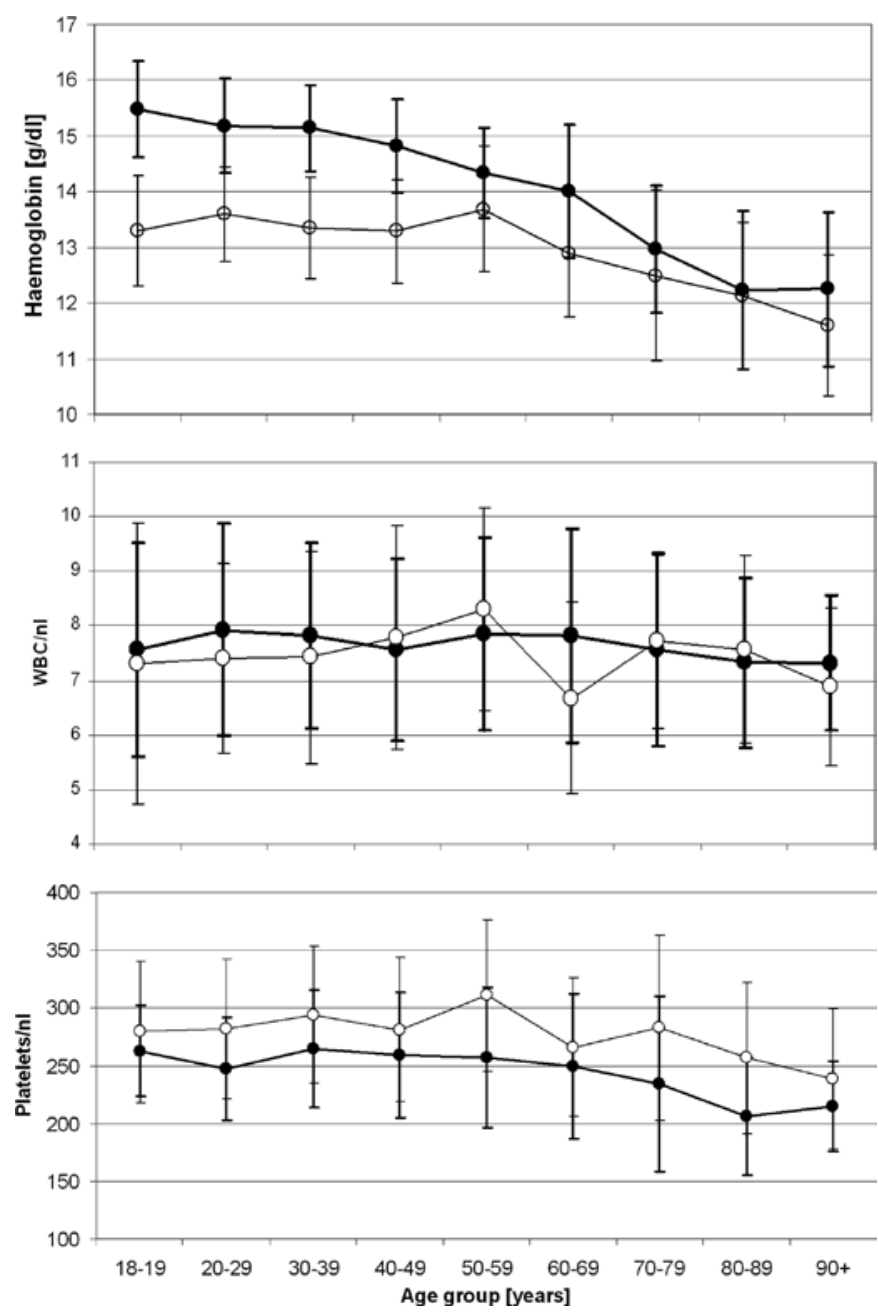

Figure 1. Haemoglobin levels, white blood and platelet counts by age group in the study population of 1,724 hospitalised individuals in the absence of a known haematological history (908 women aged 18 to 101 years and 816 men aged 18 to 96 years) $-\bullet-$, men; -o-, women.

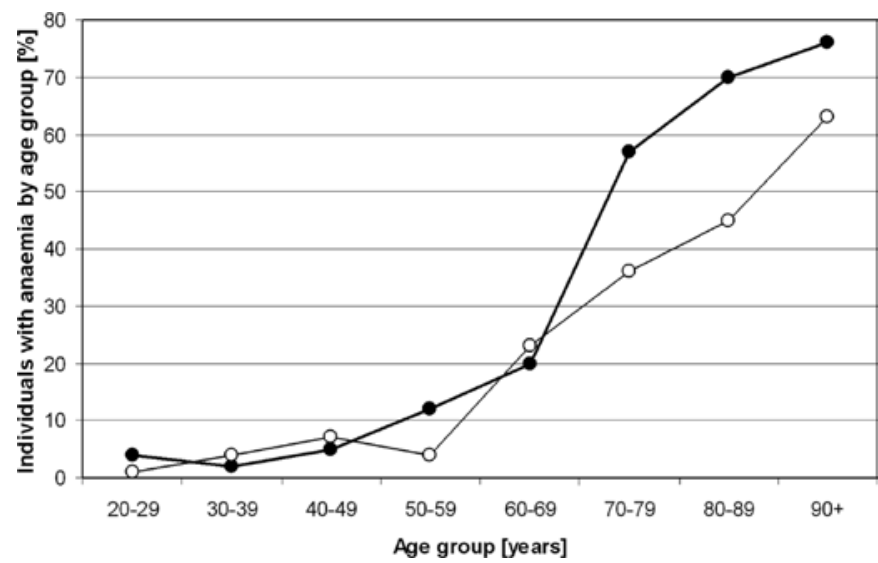

Figure 2. Percentage of individuals with anaemia in the University of Heidelberg Medical Center study population according to the WHO criteria

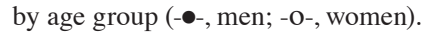

for male individuals $(\mathrm{p}=0.008)$, but not for female subjects $(\mathrm{p}=0.23)$. Despite the age-dependent decreasing trend for leukocyte values, these remained within the reference interval

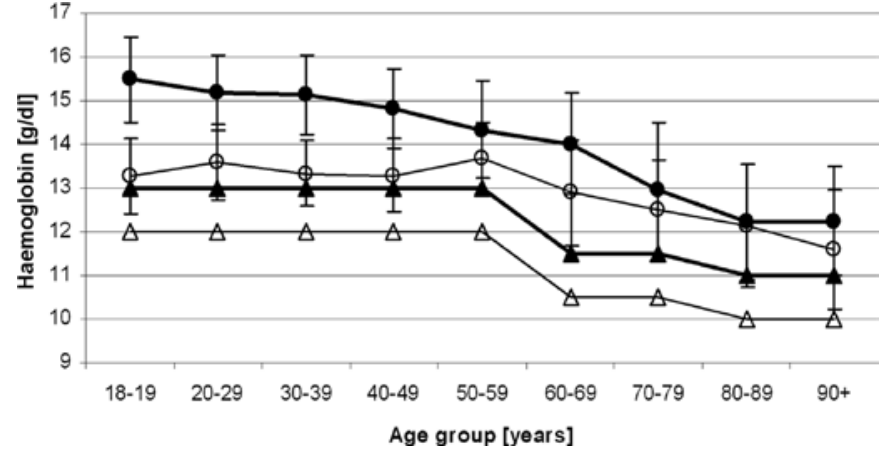

Figure 3. Age-adjusted mean values of lower haemoglobin levels (-๑-, men; -0-, women) minus $2 \mathrm{SD}$ in the University of Heidelberg Medical Center study population, which allow the proposal of a novel age-adjusted definition of anaemia for elderly Caucasians (- $-\mathbf{-}$, men; $-\Delta^{-}$, women).

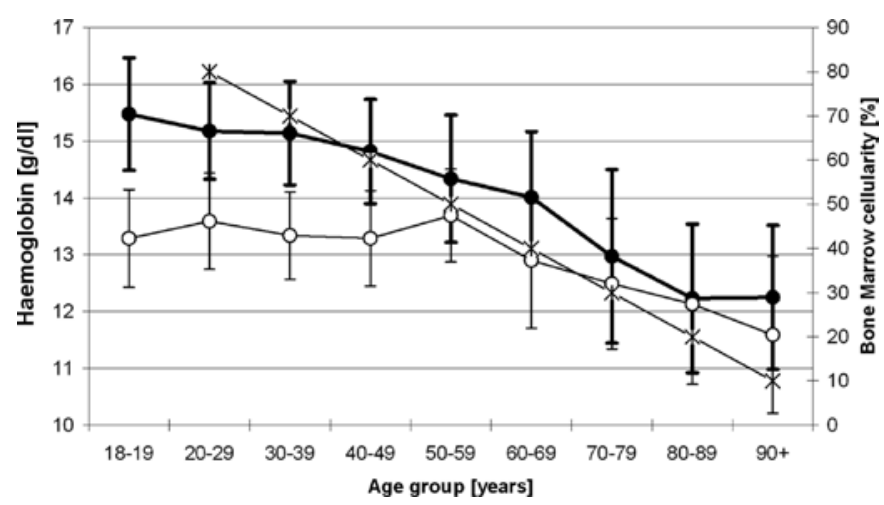

Figure 4. Relationship between haemoglobin levels found in the present study and the course of age-dependent bone marrow cellularity $(-\bullet-$, men; -o-. women; -x-, bone marrow cellularity).

in use by the University of Heidelberg Medical Center (Fig. 1). A comparison of differential blood counts among the various age groups and genders was quite inconsistent.

\section{Discussion}

The diagnosis and assessment of anaemia is an essential part of everyday clinical practice and is gaining importance, particularly in view of the increasingly ageing population in the Western world. Anaemia is a common disorder in the elderly and, while it is typically mild in this population, it has been associated with substantial morbidity and mortality (24). It is therefore important to initially determine whether a patient is, in fact, anaemic, or whether his/her low haemoglobin level is a phenomenon of the expression of old age. This may be difficult to assess if a record of previous blood counts is unavailable and a physician is forced to make a judgement on the basis of a specific population's haemoglobin distribution.

In the 1960s the World Health Organization (WHO) carried out a number of studies on nutritional anaemias of pregnancy in India, Israel, Mexico, Poland and Venezuela. Based on these data, in 1968, the WHO arbitrarily defined 
Table II. Geriatric assessment based on performance status (ECOG or Karnofski-Index) and the presence of comorbidities (upper panel) $(50,51)$ and proposal of a novel age-adjusted definition of anaemia for elderly Caucasians.

Fit patient

ECOG 0 or Karnofski index 90-100\%

No comorbidities
Frail patient

$\mathrm{ECOG} \geq 1$ or Karnofski index $\leq 80 \%$

Comorbidities

\begin{tabular}{|c|c|c|c|c|c|}
\hline \multicolumn{3}{|c|}{ Men } & \multicolumn{3}{|c|}{ Women } \\
\hline$\leq 59$ years & $\leq 79$ years & $\geq 80$ years & $\leq 59$ years & $\leq 79$ years & $\geq 80$ years \\
\hline $13.0 \mathrm{~g} / \mathrm{dl}$ & $11.5 \mathrm{~g} / \mathrm{dl}$ & $11.0 \mathrm{~g} / \mathrm{dl}$ & $12.0 \mathrm{~g} / \mathrm{dl}$ & $10.5 \mathrm{~g} / \mathrm{dl}$ & $10.0 \mathrm{~g} / \mathrm{dl}$ \\
\hline
\end{tabular}

haemoglobin limits, which became the standard in the diagnosis of anaemia and which are still being used at present. Accordingly, the diagnosis of anaemia is considered when haemoglobin levels are lower than $13.0 \mathrm{~g} / \mathrm{dl}$ in males, $12.0 \mathrm{~g} /$ $\mathrm{dl}$ in non-pregnant females and $11 \mathrm{~g} / \mathrm{dl}$ in pregnant females for individuals residing at sea level (25). From the time of the establishment of these first guidelines in 1968, there was difficulty in precisely defining normality in the populations that were studied and in deducing haemoglobin limits that were generally binding for all populations worldwide. In addition, since 1968, numerous parameters that may affect haemoglobin levels (environmental and nutritional factors, lifestyle and others) have changed quite considerably in the Western world. In addition and most importantly, individuals beyond 65 years of age and racial and ethnic differences were not considered in these studies. Also, numerous factors have been described that affect blood counts in the elderly. Reduced numbers of haematopoietic stem cells, the finite number of cell divisions (18), a defect in progenitor cell proliferation (19), the inability to sufficiently mobilize such progenitors (6), and the lack of hormonal stimulation or the reduced response to hormonal stimulation (20-23) are a few examples of conditions that may be associated with reduced haemoglobin levels in the absence of an apparent illness. A considerable decline in oxygen need due to the diminishing body mass and/or physical activity which is reflected in the relationship between haemoglobin and body mass index are also factors that contribute to low haemoglobin levels, and should therefore be considered $(6,19,26)$. The current definition of anaemia suggested by a WHO expert committee in 1968 is therefore not applicable to the elderly, and urgently needs to be updated $(25,27-31)$.

Despite the fact that numerous studies have been carried out in the last 40 years showing aberrant haemoglobin distributions within distinct populations, most authors have dismissed the need for a modification of the lower haemoglobin reference values solely on the basis of an individual's age (3-12,32). This is essentially due to the fear of incorrectly underdiagnosing anaemia once age-related haemoglobin changes are considered, and consequently accepting an overdiagnosis of anaemia when an individual's age is not being taken into account (33). Several studies have aimed to determine the most relevant causes of anaemia in the elderly. In addition to well-described causes such as chronic disease, infection, iron or vitamin B12 deficiency, renal or liver failure, in up to $36 \%$ of individuals the origin of anaemia was unknown $(34,35)$. In accordance with our study, the vast majority of authors identified a higher prevalence of anaemic subjects in the elderly population as compared to younger individuals. Therefore, the question arises as to whether this phenomenon is part of the physiological ageing process, or whether it is the consequence or cause of an underlying disease process as yet undiagnosed (4). Studies involving only elderly patients over a long period of time are difficult to interpret, as ageing itself is a process that increases the mortality risk as a function of time. Therefore, whether an elderly person carries an increased risk of mortality because of low haemoglobin levels or because of advanced age is still unclear. One possible explanation for low haemoglobin levels in the aged is the reduced haematopoietic activity, as determined by a decrease in bone marrow cellularity of up to $50 \%$ in individuals beyond the age of 60 years, which occurs along with a significant reduction in peripheral blood counts $(19,36)$. In one study, reduced numbers of both bone marrow erythroid and myeloid progenitors were observed to be more pronounced in elderly men than in elderly women, which may at least in part explain gender differences in the decline of haemoglobin levels in the elderly (6). Also, stem cells are subject to replicative senescence and can only perform a finite number of cell divisions, which provides an additional explanation for the age-dependent reduction in haematopoiesis (Fig. 4) (18,37-39). As demonstrated by several research groups, an age-dependent decline in bone marrow cellularity is observed after the 3rd decade of life. By contrast, in young individuals below the age of 30 , over $70 \%$ of haematopoietic cellular matter comprises the bone marrow volume and 30\% consist of degenerated marrow fat. In accordance with the following simplified formula: 100 - age (years) = bone marrow cellularity $(\%)(40,41)$, an estimate of bone marrow cellularity within single age groups can be determined, and - particularly in the elderly - a dramatic age-associated loss of bone marrow cellularity has been described by several authors (42-44). In addition, it must be taken into consideration that the bone marrow response and thus the haematopoietic response to incoming stimuli and the cellular crosstalk are reduced in aged indiciduals (Figs. 3 and 4) (19,45-47).

Even though average haemoglobin values vary from laboratory to laboratory, a working definition of anaemia in a specific population may be described by haemoglobin levels less than the mean values in a population minus $2 \mathrm{SD}$. Based 
on the results of our study data collected at the University of Heidelberg Medical Center, the proposed age-adjusted lower haemoglobin levels that would allow the diagnosis of anaemia in healthy elderly individuals are lower than the reference values that are currently being used worldwide based on the WHO studies of the 1960s (Table II).

Haemoglobin levels in healthy elders are generally lower than those in younger adults, and the differences between males and females that are noted in younger adults are continuously narrowed with increasing age (Fig. 1) $(13,48,49)$.

We therefore propose a re-definition of the diagnosis criteria for anaemia in the elderly in conjunction with geriatric assessment, which distinguishes 'fit' from 'frail' patients. A patient should be considered 'frail' when fulfilling at least 1 out of the 5 criteria that are listed for frail patients (Table II), and the WHO diagnostic criteria for anaemia should be applied in accordance with the previous WHO recommendations with lower haemoglobin limits of $\leq 12.0 \mathrm{~g} / \mathrm{dl}$ for women and $\leq 13.0 \mathrm{~g} / \mathrm{dl}$ for men. However, when a patient fulfills the criteria for a 'fit' patient, i.e., all indicated criteria are met (Table II), the age-adjusted haemoglobin levels should be used as proposed in Table II.

\section{Acknowledgements}

This work was supported by the Deutsche José Carreras Leukämie-Stiftung (DJCLS R09/20) to U.M.

\section{References}

1. Zakai NA, Katz R, Hirsch C, et al: A prospective study of anemia status, hemoglobin concentration, and mortality in an elderly cohort: the Cardiovascular Health Study. Arch Intern Med 165: 2214-2220, 2005.

2. Bohlius J, Wilson J, Seidenfeld J, et al: Recombinant human erythropoietins and cancer patients: updated meta-analysis of 57 studies including 9353 patients. J Natl Cancer Inst 98: 708-714, 2006.

3. Castro OL, Haddy TB and Rana SR: Age- and sex-related blood cell values in healthy black Americans. Public Health Rep 102 232-237, 1987.

4. Izaks GJ and Westendorp RG: Ill or just old? Towards a conceptual framework of the relation between ageing and disease. BMC Geriatr 3: 7, 2003.

5. Lugada ES, Mermin J, Kaharuza F, et al: Population-based hematologic and immunologic reference values for a healthy Ugandan population. Clin Diagn Lab Immunol 11: 29-34, 2004.

6. Nilsson-Ehle H, Jagenburg R, Landahl S and Svanborg A: Blood haemoglobin declines in the elderly: implications for reference intervals from age 70 to 88. Eur J Haematol 65: 297-305, 2000.

7. Nordin G, Martensson A, Swolin B, et al: A multicentre study of reference intervals for haemoglobin, basic blood cell counts and erythrocyte indices in the adult population of the Nordic countries. Scand J Clin Lab Invest 64: 385-398, 2004.

8. Tsang CW, Lazarus R, Smith W, Mitchell P, Koutts J and Burnett L: Hematological indices in an older population sample: derivation of healthy reference values. Clin Chem 44: 96-101, 1998.

9. Akdag R, Energin VM, Kalayci AG and Karakelleoglu C: Reference limits for routine haematological measurements in 7-14-year-old children living at an intermediate altitude (1869 m, Erzurum, Turkey). Scand J Clin Lab Invest 56: 103-109, 1996.

10. Bao W, Dalferes ER Jr, Srinivasan SR, Webber LS and Berenson GS: Normative distribution of complete blood count from early childhood through adolescence: the Bogalusa Heart Study. Prev Med 22: 825-837, 1993.

11. Serjeant GR, Grandison Y, Mason K, Serjeant B, Sewell A and Vaidya S: Haematological indices in normal Negro children: a Jamaican cohort from birth to five years. Clin Lab Haematol 2: $169-178,1980$.
12. Shiga S, Koyanagi I, Ohsaga J, Ichiyama $\mathrm{S}$ and Kannagi R: [Clinical reference values for laboratory hematology tests calculated using the iterative truncation method with correction: Part 2, reference values for white blood cell (WBC) count, WBC differential including segmented neutrophil, band neutrophil, lymphocyte, monocyte, eosinophil, basophil, platelet count and mean platelet volume]. Rinsho Byori 47: 281-288, 1999.

13. Nilsson-Ehle H, Jagenburg R, Landahl S, Svanborg A and Westin J: Haematological abnormalities and reference intervals in the elderly. A cross-sectional comparative study of three urban Swedish population samples aged 70, 75 and 81 years. Acta Med Scand 224: 595-604, 1988.

14. Marchant T, Schellenberg JA, Nathan R, et al: Anaemia in pregnancy and infant mortality in Tanzania. Trop Med Int Health 9: 262-266, 2004.

15. United_Nations: Population Division: World Population Prospects. The 2006 Revision. United Nations, New York, NY, 2007.

16. Bundesamt S: German Population until 2060. Wiesbaden, 2009.

17. Kirkwood TB and Austad SN: Why do we age? Nature 408: 233-238, 2000

18. Hayflick L: The limited in vitro lifetime of human diploid cell strains. Exp Cell Res 37: 614-636, 1965.

19. Lipschitz DA, Udupa KB, Milton KY and Thompson CO: Effect of age on hematopoiesis in man. Blood 63: 502-509, 1984.

20. Young DS: Pre-analytical variability in the elderly. Geriatr Clin Chem 19-39, 1994.

21. Carpenter MA, Kendall RG, O'Brien AE, et al: Reduced erythropoietin response to anaemia in elderly patients with normocytic anaemia. Eur J Haematol 49: 119-121, 1992.

22. Kario K, Matsuo T, Kodama K, Nakao K and Asada R: Reduced erythropoietin secretion in senile anemia. Am J Hematol 41: 252-257, 1992.

23. Nafziger J, Pailla K, Luciani L, Andreux JP, Saint-Jean O and Casadevall N: Decreased erythropoietin responsiveness to iron deficiency anemia in the elderly. Am J Hematol 43: 172-176, 1993.

24. Price EA and Schrier SL: Anemia in the elderly: introduction. Semin Hematol 45: 207-209, 2008.

25. Blanc B, Finch CA, Hallberg L, et al: Nutritional anaemias. Report of a WHO Scientific Group. WHO Tech Rep Ser 405: $1-40,1968$.

26. Lapin A and Bohmer F: [Laboratory findings in elderly patients: a forgotten aspect of laboratory medicine?]. Z Gerontol Geriatr 32: 41-46, 1999.

27. Kilpatrick GS and Hardisty RM: The prevalence of anaemia in the community. A survey of a random sample of the population. Br Med J 1: 778-782, 1961.

28. De Leeuw NK, Lowenstein L and Hsieh YS: Iron deficiency and hydremia in normal pregnancy. Medicine 45: 291-315, 1966.

29. Sturgeon P: Studies of iron requirements in infants. III. Influence of supplemental iron during normal pregnancy on mother and infant. B. The infant. Br J Haematol 5: 45-55, 1959.

30. Natvig K: Studies on hemoglobin values in Norway. V. Hemoglobin concentration and hematocrit in men aged 15-21 years. Acta Med Scand 180: 613-620, 1966.

31. Beutler E and Waalen J: The definition of anemia: what is the lower limit of normal of the blood hemoglobin concentration? Blood 107: 1747-1750, 2006.

32. Izaks GJ, Remarque EJ, Becker SV and Westendorp RG: Lymphocyte count and mortality risk in older persons. The Leiden 85-Plus Study. J Am Geriatr Soc 51: 1461-1465, 2003.

33. Melillo KD: Interpretation of laboratory values in older adults. Nurse Pract 18: 59-67, 1993.

34. Balducci L: Epidemiology of anemia in the elderly: information on diagnostic evaluation. J Am Geriatr Soc 51: S2-S9, 2003.

35. Gabrilove J: Anemia and the elderly: clinical considerations. Best Pract Res Clin Haematol 18: 417-422, 2005.

36. Vogel JM: Hematologic problems of the aged. Mt Sinai J Med 47: 150-165, 1980.

37. Wagner W, Bork S, Horn $\mathrm{P}$, et al: Aging and replicative senescence have related effects on human stem and progenitor cells. PLoS One 4: e5846, 2009.

38. Waterstrat A and Van Zant G: Effects of aging on hematopoietic stem and progenitor cells. Curr Opin Immunol 21: 408-413, 2009.

39. Rossi DJ, Jamieson CH and Weissman IL: Stems cells and the pathways to aging and cancer. Cell 132: 681-696, 2008.

40. Longo DL: Closing in on a killer: anemia in elderly people. $\mathrm{J}$ Gerontol A Biol Sci Med Sci 60: 727-728, 2005. 
41. Burkhardt R, Kettner G, Bohm W, et al: Changes in trabecular bone, hematopoiesis and bone marrow vessels in aplastic anemia primary osteoporosis, and old age: a comparative histomorphometric study. Bone 8: 157-164, 1987.

42. Aapro MS, Cella D and Zagari M: Age, anemia, and fatigue. Semin Oncol 29: 55-59, 2002.

43. Goldstein S: The biology of aging. N Engl J Med 285: 1120-1129, 1971.

44. Hartsock RJ, Smith EB and Petty CS: Normal variations with aging of the amount of hematopoietic tissue in bone marrow from the anterior iliac crest. A study made from 177 cases of sudden death examined by necropsy. Am J Clin Pathol 43: 326-331, 1965

45. Baldwin JG Jr: True anemia: incidence and significance in the elderly. Geriatrics 44: 33-36, 1989.

46. Baldwin JG Jr: Hematopoietic function in the elderly. Arch Intern Med 148: 2544-2546, 1988.
47. Eisenstaedt R, Penninx BW and Woodman RC: Anemia in the elderly: current understanding and emerging concepts. Blood Rev 20: 213-226, 2006.

48. Nilsson-Ehle H, Jagenburg R, Landahl S, Svanborg A and Westin J: Decline of blood haemoglobin in the aged: a longitudinal study of an urban Swedish population from age 70 to 81 . Br J Haematol 71: 437-442, 1989.

49. Patel KV: Epidemiology of anemia in older adults. Semin Hematol 45: 210-217, 2008.

50. Karnofsky DA and Burchenal JH: The Clinical Evaluation of Chemotherapeutic Agents in Cancer. Columbia University Press, New York, 1949.

51. Oken MM, Creech RH, Tormey DC, et al: Toxicity and response criteria of the Eastern Cooperative Oncology Group. Am J Clin Oncol 5: 649-655, 1982. 